\title{
Advantages of Pressurized-Spray Cryosurgery in Giant Cell Tumors of the Bone
}

\author{
Nevzat Dabak ${ }^{1}$, Hasan Göçer ${ }^{1}$, Alper Çıraklı \\ ${ }^{1}$ Department of Orthopedic and Traumatology, Ondokuz Mayıs University School of Medicine, Samsun, Turkey \\ ${ }^{2}$ Orthopedic and Traumatology Clinic, Kayseri Research and Training Hospital, Kayseri, Turkey
}

Background: Giant Cell Tumor is considered a benign, local and aggressive tumor. Although considered a benign bone tumor, it is still the subject of discussion and research because of the associated local bone destruction, as well as high rates of recurrence and distant metastases. Options are being developed for both surgical techniques and adjuvant therapies.

Aims: The present study evaluated the administration of cryotherapy via a pressurized-spray technique in giant cell tumors of the bone.

Study Design: Cross-sectional study.

Methods: The study included 40 patients who were treated with extensive curettage and cryotherapy at various locations during the period from February 2006 to December 2013. Informed consent forms were obtained from the participants and ethics committee approval was taken from the local ethics committee of Ondokuz Mayıs University. The pressurized-spray technique was performed using liquid nitrogen. The patients were evaluated with respect to age, gender, radiological appearance, treatment modality, duration of follow-up, skin problems and recurrence.

Results: Twenty-one patients were female; 19 were male. The average age of the patients was 33 years (range: 16-72 years), and the average duration of follow-up was 43 months (range: $12-80$ months). The average time from the onset of the complaints to the diagnosis was 6 months (range: 2-12 months). Based on the Campanacci classification: 9 patients were Grade I; 25 patients were Grade II; six patients were Grade III. The lesion was located in the femur in 14 patients, in the tibia in 11 patients, in the radius in 5 patients, in the pelvis in 4 patients, in the fibula in 3 patients, in the metatarsal in 2 patients and in the phalanges of the hand in one patient. One patient had postoperative early fracture. None of the patients had skin problems and infection. Three $(7.5 \%)$ of the patients had recurrence.

Conclusion: It was found that cryotherapy was highly effective in the lesions, especially those located in the femur and tibia and remained insufficient in the lesions expanded outside the cortex. Wound healing problems, infection and fracture risk are lower with this technique.

Keywords: Giant cell tumor, bone, surgical treatment, cryotherapy, pressurized-spray technique
Giant cell tumor of the bone (GCT) accounts for approximately $4 \%$ of the primary bone tumors (1). GCT was first defined by Cooper and Travers and then reported to have a malignancy potential by Virchow $(2,3)$. It is most often in the third to fourth decade and it is slightly more common in fe- males (1). It occurs in the metaphyseal and epiphyseal regions of the long bones, especially in the distal femur, proximal tibia and distal radius (4). Local recurrence is very common, however, distant metastasis is rare. Treatment is targeted at preserving the extremity, removing the tumor tissue com- 
pletely and preventing local recurrence. In surgical treatment, aggressive curettage is performed by preserving the cortical integrity to the greatest extent possible. Due to the high local recurrence only after the curettage, the use of local adjuvants was also reported such as phenol, liquid nitrogen, bone cement, hydrogen peroxide and alcohol $(5,6)$. In GCT, the liquid nitrogen was first used by Marcove et al. (6) as cryotherapy and reported to be an effective treatment. Marcove et al. (6) administered cryotherapy first in the metastatic carcinomas and then in the primary malignant and benign bone tumors. They reported that the local recurrence was reduced from 40$50 \%$ to $4-5 \%$ in GCT. However, some complications developed over time, such as skin necrosis, infection and fracture therefore new alternatives began to be searched. Schreuder et al. (7) administered liquid nitrogen as a pressurized-spray in aneurysmal bone cysts and reported fewer complications. The present study retrospectively evaluated the patients who were administered cryotherapy via extensive curettage and pressurized-spray technique due to GCT.

\section{MATERIALS AND METHODS}

The study included 40 patients for whom the all diagnosis and treatment stages were conducted by the same surgeon between February 2006 and December 2013 due to GCT. The age and gender of the patients, the direction-localization of the lesion and the treatment modality were investigated. All of the patients were evaluated through direct radiography (Xray), magnetic resonance imaging (MRI) and computerized tomography (CT) (Figure 1). All patients were assessed via CT for metastasis. Extended curettage and cryotherapy were performed in cases with lesions located in femur, tibia and radius. Reconstruction was performed using bone cements, grafts, plates and screws. The patients who underwent arthroplasty after open and wide intrarticular resection and who were admitted with pathological fractures were excluded from the study, since cryotherapy could not be administered sufficiently and properly. The patients were evaluated according to the Campanacci classification (8). Grade I presents with a well-defined marginal border of a thin rim and a slightly thinned but intact cortex, Grade II presents with a well-defined margin and a deformed cortex and Grade III presents with a cortical destruction and soft tissue invasion. All patients were administered surgical treatment after discussion at the tumor council and diagnosis by biopsy. Data were analyzed using Statistical Package for the Social Sciences version 15 (SPSS Inc.; Chicago, IL, USA) statistical software.

\section{Surgical technique}

A window was opened from the proper region and at a sufficient size based on the CT images and the tumor surgical principles. The macroscopic tumor mass was removed through curettage and then a wide resection was performed by high-speed burr until accessing the healthy bone. The regions with deformed cortices were covered with bone-wax. Liquid nitrogen was used in pressurized-spray form with the Brymill CRY-AC Cryogenic System (Brymill Cryogenic Systems Ellington; CT, USA). Liquid nitrogen in pressurizedspray form was applied to the window that was opened using metal vacuum flasks and probes of different height-length for 30 seconds and followed by a 30 second pause for spontaneous evaporation (Figure 2). Then the surgical area was washed with physiological saline solution to prevent from soft tissue necrosis (9). This procedure was performed three times. The surrounding soft tissues and skin were protected through wet gauze during the procedure. The ambient temperature was measured as $-190^{\circ} \mathrm{C}$ during the administration of cryogen into

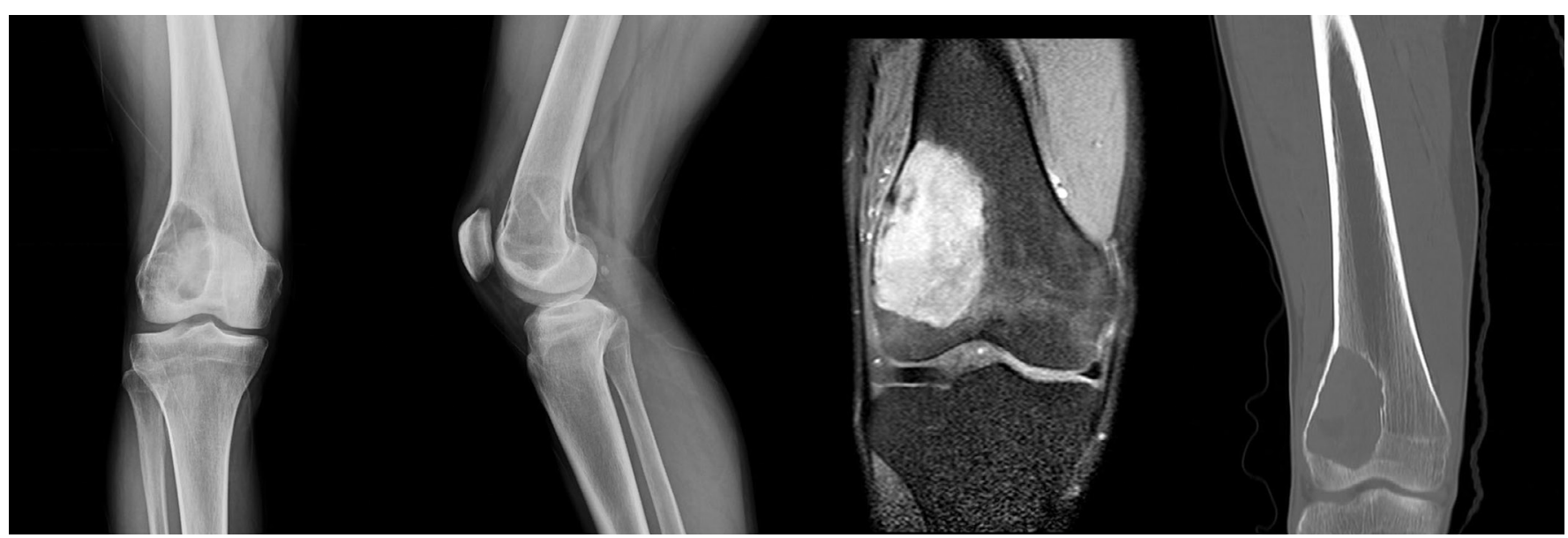

FIG. 1. X-ray, MRI and CT images of giant cell tumor(X-ray: direct radiography; MRI: magnetic resonance imaging; CT: computerized tomography) 
the cavity. Using pressurized-flush, the cement and/or plate was supported with screws based on the defect size and location or reconstruction was performed with grafts. During postoperative weeks 0 to 6 , passive/active movement was allowed without applying pressure. Between weeks 6 and 12, partial pressure was allowed. After week 12, full pressure was allowed. Recurrence and fusion were evaluated via regional direct radiography and MRI and via CT in some cases, once every three months in the postoperative year 1 , once a month in year 2, and once a year in year 3. Distant metastasis was evaluated via pulmonary CT once every 6 months.

\section{RESULTS}

Surgical curettage, cryotherapy and reconstruction were performed on 40 patients due to GCT. Out of the patients, 21 were female and 19 were male. The average age of the patients was 33 years (range: 16-72 years) and the average duration of follow-up was 43 months (range: $12-80$ months). The average time from the onset of the complaints to the diagnosis was 6 months (range: 2-12 months). Based on the Campanacci ${ }^{8}$ classification, 9 patients were Grade I, 25 patients were Grade II and 6 patients were Grade III. Among 40 patients, the lesion was located in the distal femur in 14 patients, in the tibia in 11 patients (proximal:7, distal:4), in the distal radius in 5 patients, in the pelvis in 4 patients (sacrum: 2, acetabulum: 1, ilium: 1), in the proximal fibula in 3 patients, in the metatarsi in 2 patients and in the phalanges of the hand in one patient (Figure 3). Insufficient excision was established in one patient with a lesion located in the sacrum. Three $(7.5 \%)$ out of 40 patients had recurrence. None of the patients developed skin necrosis, infection or neurovascular complications. Extended curettage and reconstruction with only bone cement were performed in 11 of the patients with femoral lesions, whereas reconstruction was performed with bone cement and screws in three patients. Loosening of the cement was established in one of the patients for whom reconstruction was performed with only cement after the curettage and intercondylar fracture was established in another (Figure 4). There was no recurrence in 2 patients for whom reconstruction was re-performed with cement and screws after removing the cement. Reconstruction was performed with cement after the curettage and cryotherapy on all of the patients with tibial lesions. Reconstruction was performed with cement after the curettage and cryotherapy in 5 patients with distal radial lesions. Recurrence was identified in 3th of 5 patients by the end of postoperative months 3, 4 and 6. All of the patients were grade III in recurrence distal radius lesions. For patients with recurrence, the cement was removed and then the curettage and reconstruction with cement

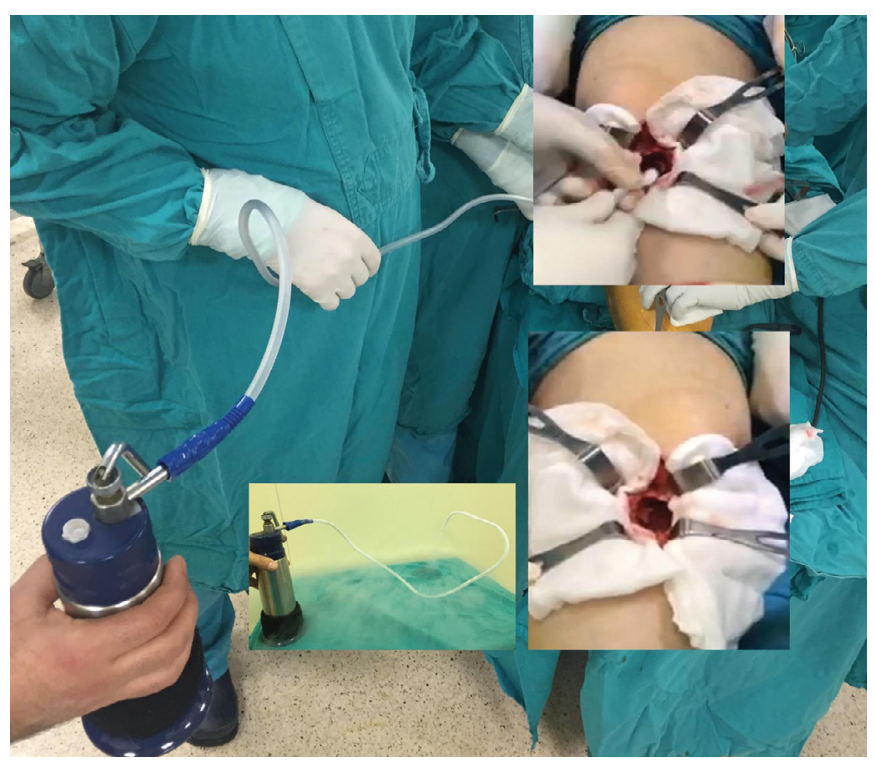

FIG. 2. Intraoperative appearance of pressurized-spray cryosurgery

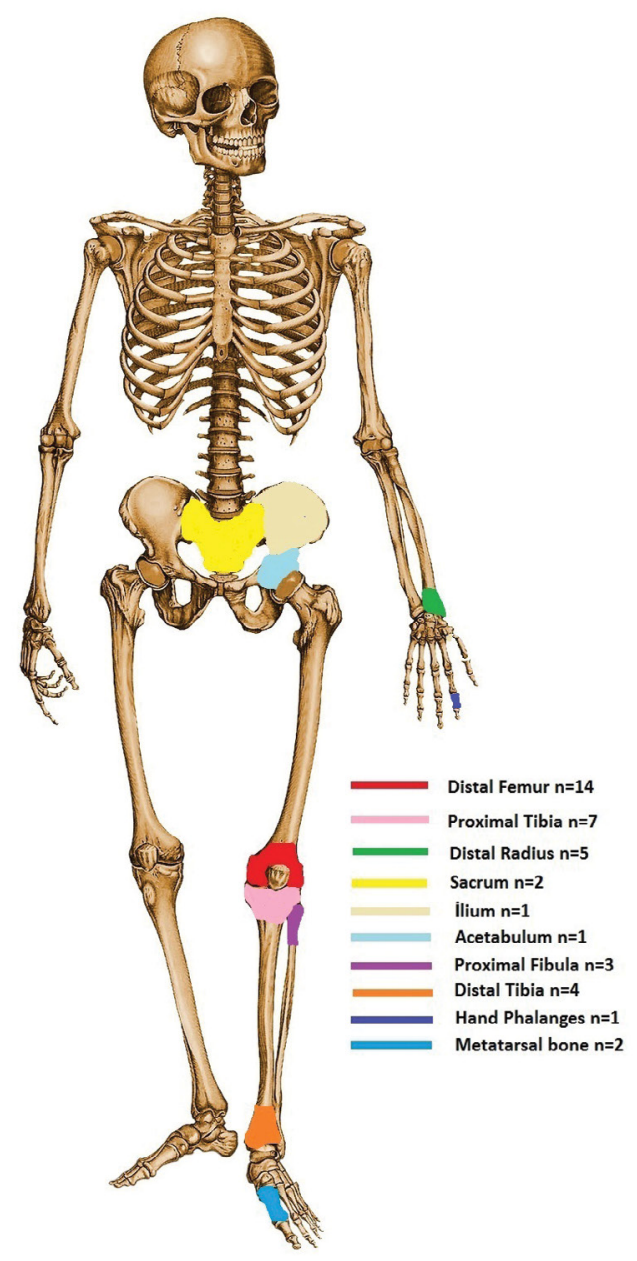

FIG. 3. Localizations of giant cell tumor on skeleton 


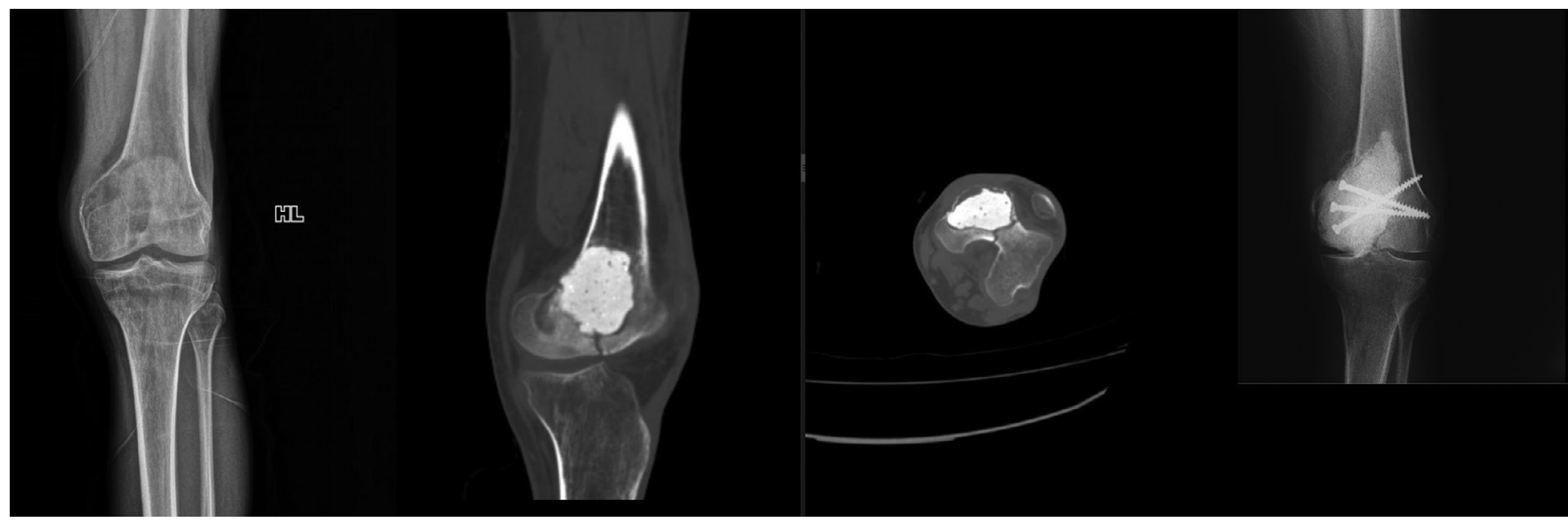

FIG. 4. Second surgical treatment of a patient with fracture established after cryotherapy

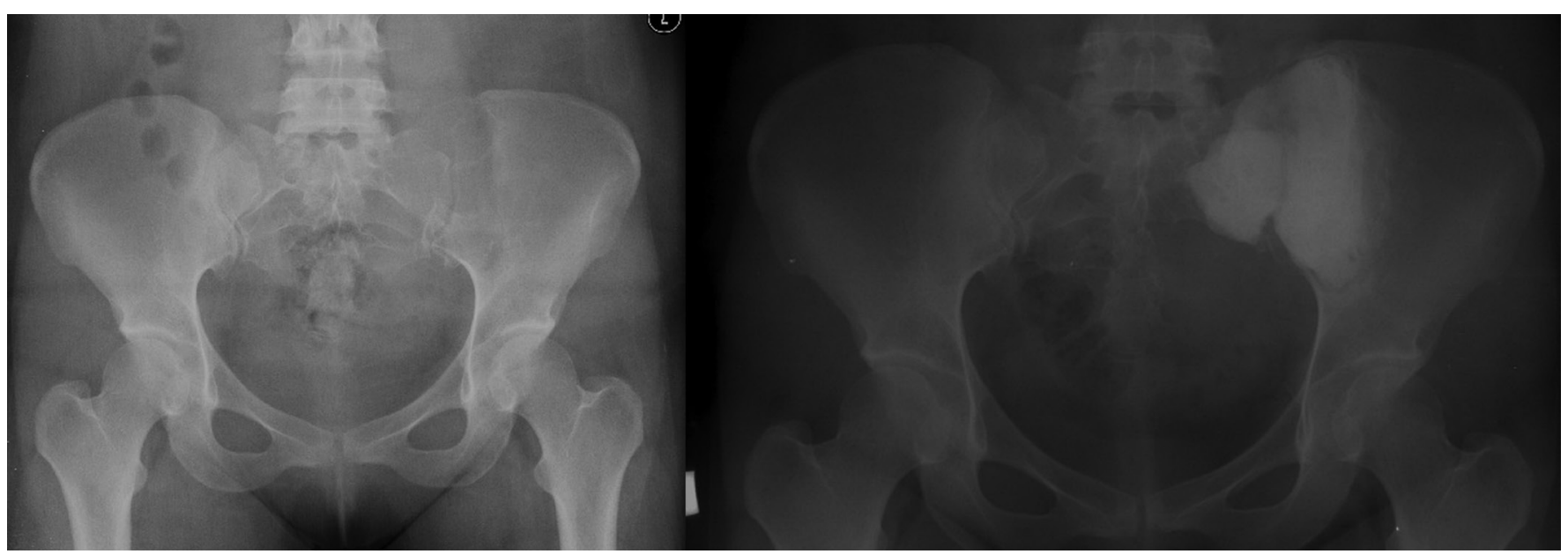

FIG. 5. Preoperative and postoperative view of sacral GCT (GCT: giant cell tumor)

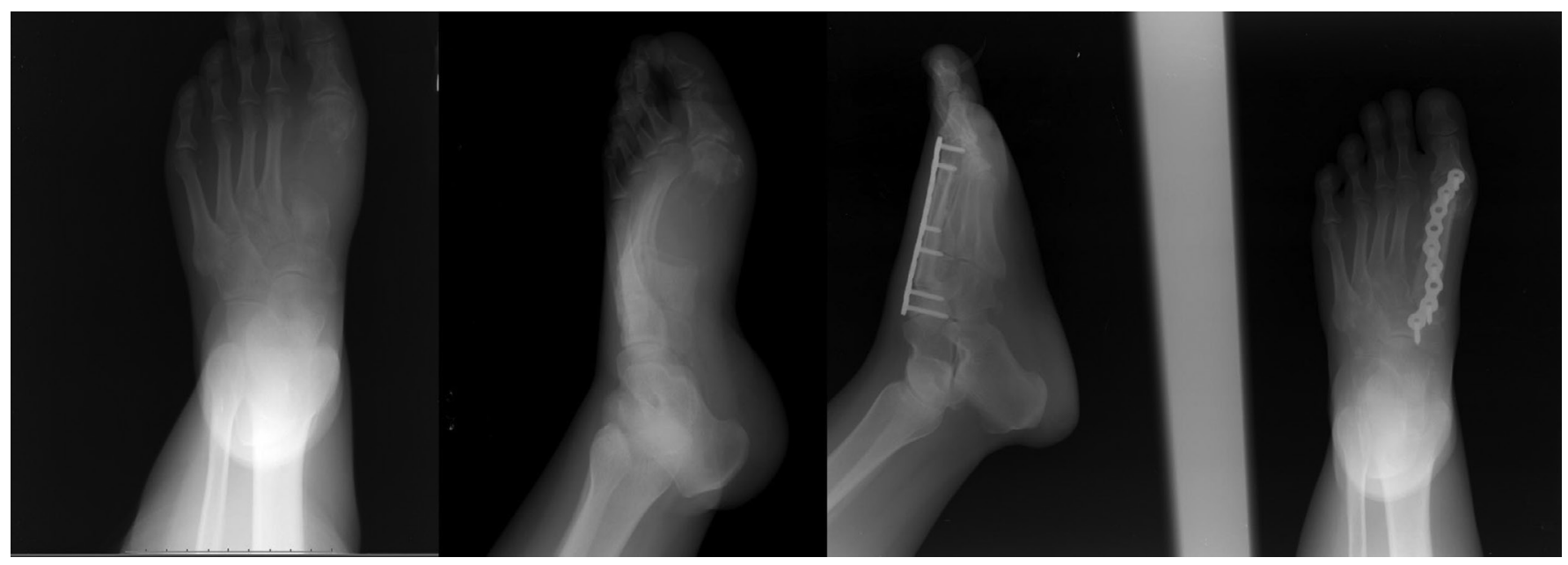

FIG. 6. Preoperative and postoperative view of metatarsal giant cell tumor 
were performed again. Insufficient excision was established in one patient with a lesion located in the sacrum. There was no consideration for surgical treatment again, the patient was controlled with denosumab (Figure 5). Extended resection and cryotherapy were performed on 3 patients with fibular lesions and none had recurrence. Total metatarsal excision and reconstruction with non-vascular autologous fibula were performed on one of 2 patients with metatarsal lesions (Figure 6). $\mathrm{Cu}$ rettage and reconstruction with cement was performed on the other patient. There was no recurrence in 2 patients. Extended resection and arthrodesis were performed in the middle phalanx on one patient with hand phalangeal lesion and there was no recurrence. One patient was found to have lung metastasis.

\section{DISCUSSION}

Giant cell tumor of the bone is considered a benign, local and aggressive tumor of the bone with unknown origin (10). Although considered a benign bone tumor, it is still a subject of discussion and research because of the local bone destruction, the high rates of recurrence and distant metastases. Options are being developed for both surgical techniques and adjuvant therapies (11-14). The number of female-male patients was close to each other and the average age was 33 years in the investigation of 40 patients. The average duration of follow-up was 48 months (range:12-80 months); however, some patients had a shorter duration of follow-up, but were still included in the study due to the present early fractures. The most common complaint was pain, which was mild at the beginning and became permanent and much severe in the following periods with the application of force $(1,8)$. Additionally, there may be swelling, restricted movement and neurological symptoms depending on the invasion site. The average time from the clinical complaints to the diagnosis was 6 months (range:2-12 months) for the patients. The diagnosis is delayed by the time that the symptoms develop, due to mechanical insufficiency and radiological signs are observed, especially in the lesions located in the pelvis and distal femur. More care should be taken in the radial lesions and the direct radiographies should be analyzed meticulously. In 4 patients with radial lesions, the lesions expanded over the cortex and had intact soft tissues.

Campanacci et al. (15) reported a recurrence rate of $27 \%$ with interlesional curettage, $7 \%$ with marginal curettage and $0 \%$ with wide resection in an analysis of 327 GCT cases; however, they did not make any evaluations regarding the use of chemical agents. Becker et al. (16) reported a recurrence rate of $49 \%$ in patients administered curettage and graft, $22 \%$ in patients administered curettage and cement and $27 \%$ in pa- tients administered curettage, phenol and cement. A higher rate of recurrence is reported with curettage and grafting alone, whereas the recurrence rate reduces to $20 \%$ with curettage, adjuvant therapy and reconstruction with cement. Cryotherapy produces a necrotic effect in the cell by intracellular crystallizing through quick freezing and slow thawing (17).

Marcove et al. (6) were the first to use the liquid nitrogen in GCT in the 1970s for cryotherapy through direct pouring and reported that it was an effective method to minimize local recurrence. Muramatsu et al. (18) performed curettage and cryotherapy in 23 patients and reported that there was no recurrence at the 45-month follow-up on average; the combination of curettage and cryotherapy was more successful than other methods. Kang et al. (19) performed curettage and cryotherapy in 9 out of 15 patients with Grade III lesions located in distal radius and reported recurrence in 2 patients and no recurrence in any of 6 patients underwent wide excision. However, it was reported that the use of liquid nitrogen by direct pouring resulted in skin necrosis, neurovascular complications and other complications such as pathological fractures $(16,20-22)$. It has become possible to apply liquid nitrogen within metal vacuum flasks as a pressurized-spray to an area and for a specific desired time using probes $(7,9)$. Due to its thrombotic effect on the microvessels supplying the tumor, even indirectly, the necrotic effect continues for one more week. Additionally, a homogeneous or a deeper effect can be achieved on irregular surfaces such as flat bones in particular via the spraying technique $(23,24)$. Cryotherapy and bone cement are the only adjuvant methods used no other methods like phenol, alcohol is not used in this study.

Cryotherapy and reconstruction with only cement were performed after extended curettage in 22 out of 25 patients with lesions located in femur and tibia. The other three patients were treated with reconstruction with screws and cement after curettage and cryotherapy. The administration of cryotherapy in a sufficient amount is very successful, easy and possible in large metaphyseal bones such as the femur and tibia by protecting the soft tissues and important structures by wide skin incision compared to other regions. In the direct-pouring technique described by Marcove et al. (6) the prophylactic internal fixation implants were started to be used more frequently due to the high risk for fracture $(25,26)$. This leads to difficulties in establishing the postoperative recurrence radiologically and also higher rates of infection. On the other hand, the use of cryotherapy as a pressurized-spray reduces the fracture risk and therefore, fixation was performed with prophylactic implant in extremely large lesions.

Surgical treatment was re-administered in three of five patients with radial lesions due to recurrence. The excision remained insufficient in these patients with intact soft tissues 
expanded outside the cortex because a safe surgical margin could not be achieved and the important neurovascular structures could not be protected. Cryotherapy can have effects deeper into the bone tissue; however, it is not used frequently enough due to its necrotic effect on the adjacent soft tissues. Llu et al. (27) conducted a meta-analysis and reported that the curettage and grafting or cement alone was not as successful as en-block resection in GCT located in distal radius. It may be preferred to achieve a negative surgical margin in the lesions associated with extensive cortical damage and soft tissue involvement as is in the low-grade malignant tumors. It was reported that the en-bloc resection and non-vascular fibular graft prevented local recurrence and did not impair the wrist functions in GCT located in distal radius (28).

Insufficient excision was established in one of the patients with lesions located in sacrum. It was decided to conservatively follow this patient with denosumab because the surgical treatment was considered risky. Local regression was observed at the follow-up and it is still closely followed. Compared to direct-pouring method, the spray technique for cryotherapy is easier to use in the bones with no regular contours such as the pelvis and it is associated with fewer potential complications. Guo et al. (29) suggested excision with wide surgical margins in giant cell tumors of the bone that were located in the pelvic region despite the additional morbidity. Balke et al. (30) reported that they achieved successful outcomes in pelvic GCT with local excision through arterial embolization.

Wide excision was performed on the patients with fibular lesions since it did not cause mechanical insufficiency of the joints and lower extremities. Cryotherapy was administered to the osteotomy line that remained in the fibula. Cryotherapy was administered to the adjacent regions by complete resection of metatarsi with the soft tissue for one of the patients with lesions located in the metatarsi since all metatarsi were involved and the soft tissue was intact. The defects were reconstructed with non-vascular fibular autografts. For other patients, wide excision, cryotherapy and reconstruction with cement were performed. A patient with a lesion located in the middle phalanx of the hand was treated by marginal resection, cryotherapy and arthrodesis.

Bone cement is used as a local filling material; however, the effect of the convected heat around is approximately 40 $50^{\circ} \mathrm{C}$, even at the center, and thereby its adjuvant effect may not be sufficient (31). The present study preferred to primarily employ bone cement and if possible, alone, because it has a local heat effect, provides early stability and allows for optimum assessment at follow-up. However, a solid cage was produced by placing the cross screws into the opposite cortex and the cementing was performed at the final stage in cases where mechanical insufficiency might develop with wide resection.
Malawer et al. (26) reported a recurrence rate of 2.3\% after cryosurgery; however, they underlined the intraoperative soft tissue and neurovascular tissue damage, and the pathological fracture in postoperative six $(5.9 \%)$ cases. It was reported that the cryotherapy affected more deeply due to the pressurizedspray application and had fewer adverse effects on the skin and the neurovascular tissues due to the fast evaporation $(9,16,21)$. None of the patients developed soft tissue necrosis, infection and neurovascular complications.

Cryotherapy causes necrosis and osteoid damage in the bone after the direct-pouring method, leading to delayed reossification and bone healing; therefore, minor traumas may result in fractures. Based on the depth of the necrotic effect of the cryotherapy, the recovery time may last from six weeks to six months (32). However, the fracture risk is lower with pressurized-spray technique compared to the direct-pouring method since it evaporates fast despite the deeper effect $(7,9,23)$. A patient with a femoral lesion had early fracture. Such fractures developed because this patient started to work in a heavy job in the early period (week 4). The cement was removed and reconstructed was performed with spongiosis screws and cement. In order to avoid postoperative fractures, early passive movement was initiated in the patients and applying force was avoided at least until week 6 . Then, stepping was allowed gradually to the extent the pain was tolerated. After week 12, full application of pressure was allowed. However, it may take longer for the rehabilitation of the patients who cannot tolerate the application of force and who develop muscular atrophy.

Some suggest to administer active chemotherapy or radiotherapy in cases where surgical treatment cannot be administered and there is an extensive soft tissue invasion, especially in Grade III patients; however, malignant transformation may occur $(33,34)$. In such cases, more radical surgical treatments may be preferred, if applicable. Denosumab may be preferred for such large lesions that cannot be operated or in order to reduce the lesion to a resectable size before surgery and several studies have demonstrated its efficacy (35). Because there may be recurrence in such cases, the patient should be followed at frequent intervals. Though rare, lung metastases are reported in GCT (36). A patient from the present study, who had lung metastasis, was Grade II with distal femur localization and no additional treatment was planned since there was no progression in the lesion upon the close follow-up.

The present study is limited by a patient population comprising patients at various stages, the lack of a single method for reconstruction and the lack of a comparative control group. In conclusion, cryotherapy is a very effective adjuvant method for the lesions in bones such as the femur and tibia, where the soft tissue can be protected and there is no invasion to the soft tissues. The pressurized-spray technique of 
cryotherapy is preferred due to the need for reduced amounts of liquid nitrogen and minimized soft tissue complications and fracture risk.

Ethics Committee Approval: Ethics committee approval was received from the local ethics committee of Ondokuz Mayıs University.

Informed Consent: Informed consent forms were obtained from the participants.

Peer-review: Externally peer-reviewed.

Author contributions: Concept - N.D., H.G.; Design N.D., H.G., A.Ç.; Supervision - N.D., H.G., A.Ç.; Resource - N.D., H.G., A.Ç.; Materials - H.G., A.Ç.; Data Collection and/or Processing - H.G., A.Ç.; Analysis and/or Interpretation - H.G., A.Ç.; Literature Search N.D., H.G., A.Ç.; Writing - H.G., A.Ç.; Critical Reviews - N.D.

Conflict of Interest: No conflict of interest was declared by the authors.

Financial Disclosure: The authors declared that this study was received no financial support.

\section{REFERENCES}

1. Ghert MA, Rizzo M, Harrelson JM, Scully SP. Giant-cell tumor of the appendicular skeleton. Clin Orthop Relat Res 2002;400:201-10. [CrossRef]

2. Cooper A, Travers B. Surgical Essays. London: Cox\&Son; 1818.

3. Virchow R. Die Krankhaften Geschwulste. Berlin: Hirschwald; 1846.

4. Campanacci M. Giant cell tumor. In: Gaggi A, editor. Bone and softtissue tumors. Bologna: Springer-Verlag; 1990:17-53. [CrossRef]

5. Moon MS, Kim SS, Moon JL, Kim SS, Moon H. Treating giant cell tumours with curettage, electrocautery, burring, phenol irrigation and cementation. J Orthop Surg 2013;21:209-12.

6. Marcove RC, Weis LD, Vaghaiwalla MR, Pearson R, Huvos AG. Cryosurgery in the treatment of giant cell tumor of bone. A report of 52 consecutive cases. Cancer 1978;41:957-69. [CrossRef]

7. Schreuder HW, Veth RP, Pruszczynski M, Lemmens JA, Koops HS, Molenaar MV. Aneurysmal bone cysts treated by curettage, cryotherapy and bone grafting. J Bone Joint Surg Br 1997;79:20-5. [CrossRef]

8. Campanacci M. Giant-cell tumor and chondrosarcoma. Grading, treatment and results. Recent Results Cancer Res 1976;54:257-61.

9. Dabak N, Tomak Y, Piskin A, Gulman B, Ozcan H. Early results of a modified technique of cryosurgery. Int Orthop 2003;27:249-53. [CrossRef]

10. Fletcher CDM, Unni KK, Mertens F. Pathology and genetics of tumors of soft tissue and bone. Lyon: IARC Press; 2002.

11. Sung HW, Kuo DP, Shu WP, Chai YB, Liu CC, Li SM. Giant cell tumor of bone: Analysis of two hundred and eight cases in Chinese patients. J Bone Joint Surg Am 1982;64:755-61.
12. Saglik Y, Yildiz Y, Karakas A, Ogüt H, Erekul S. Giant cell tumor of bone. Bull Hosp Jt Dis 1999;58:98-104.

13. Balke M, Schremper L, Gebert C, Ahrens H, Streitbuerger A, Koehler G, et al. Giant cell tumor of bone: treatment and outcome of 214 cases. J Cancer Res Clin Oncol 2008;134:96978. [CrossRef]

14. Kivioja AH, Blomqvist C, Hietaniemi K, Trovik C, Walloe A, Bauer $\mathrm{HC}$, et al. Cement is recommended in intralesional surgery of giant cell tumors: a Scandinaviansarcoma group study of 294 patients followed for a median time of 5 years. Acta Orthop 2008;79:86-93. [CrossRef]

15. Campanacci M, Baldini N, Boriani S, Sudanese A. Giant cell tumor of bone. J Bone Joint Surg Am 1987;69:106-14.

16. Knochentumoren A, Becker WT, Dohle J, Bernd L, Braun A, Cserhati $\mathrm{M}$, et al. Local recurrence of giant cell tumor of bone after intralesional treatment with and without adjuvant therapy. J Bone Joint Surg Am 2008;90:1060-7. [CrossRef]

17. Gill W, Fraser J, Carter DC. Repeated freeze-thaw cyclesin cryosurgery. Nature 1968;219: 410-3. [CrossRef]

18. Muramatsu K, Ihara K, Taquchi T. Treatment of giant cell tumor of long bones: Clinical outcome and reconstructive strategy for lower and upper limbs. Orthopedics 2009;32:491. [CrossRef]

19. Kang L, Manoso MV, Boland PJ, Healey JH, Athanasian EA. Features of grade 3 Giant Cell Tumors of the distal radius associated with successful intralesional treatment. J Hand Surg Am 2010;35:1850-7. [CrossRef]

20. Blackley HR, Wunder JS, Davis AM, White LM, Kandel R, Bell RS. Treatment of giant cell tumors of long bones with curettage and bone grafting. J Bone Joint Surg Am 1999;81:811-20.

21. Veth R, Schreuder B, van Beem H, Pruszczynski M, de Rooy J. Cryosurgery in aggressive, benign and low-grade malignant bone tumours. Lancet Oncol 2005;6:25-34. [CrossRef]

22. Abdelrahman M, Bassiony AA, Shalaby H, Assal MK. Cryosurgery and impaction subchondral bone graft for the treatment of giant cell tumor around the knee. HSS J 2009;5:123-8. [CrossRef]

23. Lee RJ, Mayerson JL, Crist M. Fracture risk with pressurizedspray cryosurgery. Am J Orthop 2011;40:105-9.

24. Schreuder HW, Pruszczynski M, Veth RP, Lemmens JA. Treatment of benign and low-grade malignant intramedullary chondroid tumours with curettage and cryosurgery. Eur J Surg Oncol 1998;24:120-6. [CrossRef]

25. Malawer MM, Dunham W. Cryosurgery and acrylic cementation as surgical adjuncts in the treatment of aggressive (benign) bone tumors. Analysis of 25 patients below the age of 21. Clin Orthop Realt Res 1991;262:42-57.

26. Malawer MM, Bickels J, Meller I, Buch RG, Henshaw RM, Kollender Y. Cryosurgery in the treatment of giant cell tumor. A long-term follow up study. Clin Orthop Relat Res 1999;359:176-88. [CrossRef]

27. Liu YP, Li KH, Sun BH. Which treatment is the best for giant cell tumors of the distal radius? A meta-analysis. Clin Orthop Relat Res 2012;470:2886-94. [CrossRef]

28. Taraz-Jamshidi MH, Gharadaghi M, Mazloumi SM, HallajMoghaddam M, Ebrahimzadeh MH. Clinical outcome of enblock resection and reconstruction with nonvascularized fibular 
autograft for the treatment of giant cell tumor of distal radius. $J$ Res Med Sci 2014;19:117-21.

29. Guo W, Sun X, Zang J, Qu H. Intralesional excision versus wide resection for giant cell tumor involving the acetabulum: which is better? Clin Orthop Relat Res 2012;470:1213-20. [CrossRef]

30. Balke M, Streitbuerger A, Budny T, Henrichs M, Gosheger G, Hardes J. Treatment and outcome of giant cell tumors of the pelvis. Acta Orthop 2009;80:590-6. [CrossRef]

31. Wilkins RM, Okada Y, Sim FH, Chao EYS, Gorgki J. Methyl methacrylate replacement of subchondral bone: A biochemical and morphologic analysis. In: Enneking WF, editor. Limbs paring surgery in musculoskeletal oncology. New York: ChurchillLivingstone; 1987.

32. Gage AA, Greene GW Jr, Neiders ME, Emmings FG. Freezing bone without excision. An experimental study of bonecell destruction and manner of regrowth in dogs. JAMA 1966;196:770-4. [CrossRef]
33. Shi W, Indelicato DJ, Reith J, Smith KB, Morris CG, Scarborough MT, et al. Radiotherapy in the management of giant cell tumor of bone. Am J Clin Oncol 2013:36:505-8. [CrossRef]

34. Ruka W, Rutkowski P, Morysinski T, Nowecki Z, Zdzienicki M, Makula D, et al. The megavoltage radiation therapy in treatment of patients with advanced or difficult giant cell tumors of bone. Int J Radiat Oncol Biol Phys 2010;78:494-8. [CrossRef]

35. Niu X, Zhang Q, Hao L, Ding Y, Li Y, Xu H, et al. Giant Cell Tumor of the extremity: retrospective analysis of 621 Chinese patients from one institution. J Bone Joint Surg Am 2012;94:461-7. [CrossRef]

36. Demirsoy U, Karadogan M, Selek O, Anik Y, Aksu G, Müezzinoglu B, et al. Golden bullet-denosumab: early rapid response of metastatic giant cell tumor of the bone. J Pediatr Hematol Oncol 2014;36:156-8. [CrossRef] 